\title{
The challenges of undocumented migrant childhood
}

\section{KEYWORDS}

migrant children, incorporation, education, unauthorized status

\begin{abstract}
Albański Łukasz, The challenges of undocumented migrant childhood. Kultura - Społeczeństwo - Edukacja nr 1(13) 2018, Poznań 2018, pp. 181-199, Adam Mickiewicz University Press. ISSN 2300-0422. DOI 10.14746/ kse.2018.13.14.

This article examines the concept of undocumented childhood. Undocumented children have to navigate between protected (as minors) and unprotected (as young adults) contexts. Therefore, they live not only in a relatively difficult situation as children staying in another country, but also face other risks due to their uncertain futures. Their situation calls for a re-examination of the frame that has been triggered to incorporate them. In particular, one may ask: what does it mean to provide children with rights and protections that ultimately expire. Thus, the article aims to bring the discussion about children as a minority group back. It helps to assure that migrant children will be considered as children first, and not as foreigners.
\end{abstract}

This articles considers the concept of undocumented migrant childhood from the perspective of sociology. In doing so, it aims to complement different areas of study on undocumented migrant childhood such as educational studies to better understand the complexity of the undocumented migrant childhood concept. As a discipline from which to consider the undocumented migrant childhood concept, sociology offers a good vantage point for examining certain tensions between being classified as a minor and being tainted with the social stigma of undocumented migration. Sociology provides a critical examination of the idea of childhood in regard to the importance of the transition into adulthood. Children are trapped in the mindset of the adult in which children are portrayed as symbolically 
important figures of future adults (release from the authority of the adult one day) if still powerless and passive individuals for now. Therefore, social rules on how to socialize children, how to educate them and who has the responsibility for bringing them up are core elements in every society.

The intersectionality of childhood and undocumented migration places children in a precarious position as developing into adults, because they are left with the disadvantage of their uncertain future when they reach maturity (Gonzales, 2011). Moreover, the challenges of living as undocumented migrant children effect on integration into institutions and access to basic social rights (Bean et al., 2011). Although undocumented migrant children have been recognized as invisible victims of immigration restrictions, it does not provide the greater recognition of their inherent rights as children (PICUM, 2008). Most developed countries experience the tensions between the needs to protect migrant children and the needs to defend national borders. In times, when state policies face towards a migrant crisis, the needs for security tilt the balance in favor of lowering of protections for undocumented migrant children (Spencer, 2016). Additionally, increased restrictions on citizenship can push undocumented migrant children out on the fringes of society and reduce their chances to overcome a handicap of marginal membership status before becoming adults.

The article begins with a consideration of the critical role of children in relation to the future of each society that places them at the center of the debate on citizenship and migration. It explores some of the core ideas about migrant childhood with particular regard to incorporation and public schooling. The article delves into what is socially constructed as undocumented migrant childhood. It is argued that the dominant discourses on undocumented migrant childhood fail to recognize the agency of children in the developing world while traditional notions of childhood as a time of innocent and adult-dependency are challenged by the reality of undocumented migrant lives. Building on this, the article aims to bring attention to the transitional aspect of undocumented childhood. Careful considerations should be given to issues of coming of age, the representation of migrant children as a minority group and their legal incorporation into the host society.

\section{Global perspectives on childhood}

The role of children is justified by their strategic position in every society. Children are tied to the survival of a society and to the transmission of its cultural values. The role of children is thus everywhere subject to control and regulation. 
In contemporary studies of childhood, sociologists reveal the norms governing childhood and traditions of making normative judgements on the child (BühlerNiederberger, 2010). Sociologists of childhood lays a strong emphasis on the social construction of childhood rather than treats it as a relatively determined and universal trajectory of development (Corsaro, 2011). In their classical work, which attempted to establish a new paradigm of social understanding of childhood, James and Prout (1990: 8) declared that childhood, as distinct from biological immaturity, is neither a natural nor a universal feature of human groups but appears as a specific structural and cultural component of many societies. ${ }^{1}$ There has been a concerted attempt in a sociology of childhood to differentiate the field of the historically and culturally specific research on the constitution of childhood in and through discourse from other approaches to childhood which promote the description of childhood within epistemological and methodological traditions associated with positivism. Moreover, the break with the assumptions of developmental psychology and traditional socialization frameworks, which cast children primarily in the role of the next generation's adults (reproducing the biological and social order), has fostered a heightened sensitivity to interpretive analysis on social relations, contexts, meanings, and social structure (Mayall, 1994).

Childhood studies scholars suggest that the idea of childhood is profoundly shaped by the child-adult dualism (James, 2007). The dominant discourses on naturalizing the child have reified the child as a construct of the other, who is perceived as dependent (passive, vulnerable, unable to speak for themselves), innocent (simple, ignorant) and cute (lovely objects to be watched and discussed). Moreover, traditional notions of childhood as a time of innocent and adult-dependency have espoused the description of childhood in, more or less, universal terms, thereby undermining the diversity and complexity of childhood(s). In his postmodern critique of dominant interpretations on childhood, for instance, Kinchloe (2002: 76) claimed that such viewpoints have often equated difference with deficiency and sociocultural construction with the natural. Childhood studies scholars postulate to reintroduce the term childhood by challenging much that has been approved of modern childhood, framed in terms of a-historical "becoming adultsin-the-making" (Uprichard, 2008).

The contemporary line of critique in childhood studies even moves beyond the adult-child dualism in (what has been called vaguely) Western countries and emphasizes the need to take roots in a global context. In the words of Canella

${ }^{1}$ Childhood is to be understood as a social construction while biological immaturity is an universal and natural feature of human beings. 
(2002: 8), the aim of childhood studies is to generate a childhood studies that critiques itself, attempts to decolonize, and struggles to construct partnerships with those who are younger in the generation of human possibility. Global oriented childhood studies generally mean to broaden theoretical perspectives on childhood in a multicultural universe. One of the benefits from such approaches is to grasp the experience of childhood that transcends nation-state borders. Some issues such as migration affect children across national borders and cultures. Moreover, the meaning of global childhood is recognized beyond the figure of the normative Western child. The crucial point of global childhood studies is therefore clarified by the assumption that the image of the child is Western derived and that distorts all other images of children around the world. It means that childhood studies struggle to reconcile the effort to work on behalf of all children with the respect of global and cultural differences.

Two topics of discussion on childhood seem to be particularly relevant to show further implications for new approaches to childhood based on a global perspective: childhood as a discursive construction and children as a minority group. The first, it indicates that the child is constituted through various forms of discourse. In this sense, Jenks (1996: 32) defines the child as a status of person which is comprised through a series of, often heterogeneous, images, representations, codes and constructs. In other words, the child is not always and everywhere understood in the same way. Moreover, it is argued that it is more accurate to use the plural of childhood rather than the singular in order to capture a set of cultural discourses that underline the contingent character of childhood(s). The latter, the focus is on the capacity of children to form a minority group. It attempts to generate new possibilities for children in order to obtain legal status and to modify current children's rights to account for gender specific and cultural violations.

\section{Defining undocumented child migrants}

The role of children in the process of migration, how is perceived, exists between the opposite poles of the migration debate. On the one side, children's presence and participation in processes of migration constitutes a central axis of family migration while, on the other, migrant children are depicted as victims - vulnerable, innocent and at risk of corruption and exploitation. In the decision to immigrate, adults are often motivated to build a better future for their families, and children in particular. The child is also seen as a factor that motivates to keep adult family members together and reunite them after a time of absent. When a whole family 
moves, children usually form the front line of the process of integration in the place of arrival, because children often learn the language and social conventions faster than adults and therefore they act as interpreters and negotiators for family members. On the contrary to the central role of children in explaining the pattern of migratory decisions made by adults, migrant children are often conspicuously absent from close scrutiny (for instance, official statistics) and it is still unusual to hear the voices of migrant children themselves (James, 2007). It is even more powerfully evident, at the time of writing this article, when Europe is in the midst of the migrant crisis, screens are dominated by images of people attempting to reach the EU borders and its premise of a better life. Most of them are men, but occasionally the camera focuses on women and children who are usually depicted as a category of those more dependent and vulnerable. Moreover, for children, there is poor recognition of the diversity of their experiences and clumsy attempt to understand the issues from their perspectives. Thus, the most obvious figures emerges from media coverages are children as victims.

The migrant crisis has made the situation of migrant outside Europe even more acute, since migration comes to be perceived as an issue of security than merely one of economics or culture. The images of migrants and refugees as illegals, welfare scroungers and potential terrorists have turned them into the objects of public scrutiny. In this climate, migrant childhood has given added urgency to the debate about citizenship and diversity, but much of the focus of concern has been directed at young people (Spencer, 2016). Child migrants (outside Europe) have been deliberately depicted as victims at risk of global maladies such as inequality, poverty, war, terrorism. By contrast, once they approach the age of adolescent, migrant youth tend to be increasingly perceived as a potential threat to the social order in European societies.

The unequal power relations that are inherent in contemporary forms of migration shows the difference between those who are in charge of time-space compression, who really see it and turn it to advantage, and those who are on the move, but they do not take charge of the process in the same way. Massey (1994: 149) refers this distinction as a power-geometry. Bhabha (1992: 321) writes that the globe shrinks for those who own it; for the displaced or dispossessed, the migrant or refugee, no distance is more awesome than the few feet across borders or frontiers. For migrant children (and undocumented migrant children in particular) who find themselves in a very vulnerable position as children and foreigners, the distance can seem infinitely vast. Moreover, the cost of migration comes high as a result of the implementation of more restrictive measures for preventing people without documents from reaching European borders. Dire consequences are a growing 
number of undocumented child migrants and a substantial rise in human trafficking and it is only children with resources who can move a considerable distance from their homes. A small portion of attention has been to be paid to undocumented child migrants in Europe, yet the picture of contemporary child migration could be more complex. For instance, more prosperous countries in Africa and Asia have also received people from their poorer and war-affected neighbors.

It is not possible to consider the child migrants as a coherent group, since they vary from obvious demographic, social and cultural divisions. It is therefore understood as an umbrella term to distinct migrants who are under the age at which they become adults. Moreover, children, in most cases, do not appear separately from adults in the statistics, and it is often necessary to read between the lines to get an understanding of the main issues that affect children. These difficulties further contribute to the conditions in which some children are highlighted and others become hidden. Undocumented migrant children constitute a category under a deep veil of invisibility. Undocumented migration is usually interpreted as the taint of illegal entry which borrows from the deep-seated fears of strangers that lurk at the nation-state boundaries. Moreover, it is almost impossible to cease believing in the power of legal-illegal relations. Or at least, when the case is addressed to deal with strangers and non-citizens. Through their socialization process, children learn and incorporate the standpoint of the wider society of what it would be like to possess a particular stigma attached to being both undocumented and invisible. They learn far-reaching consequences of possessing it.

Undocumented child migrants as a category comes as a result of two possibilities - undocumented settlement and unaccompanied minor migration. The former is associated with restrictions that put upon labor migrant families. Until 1980s, undocumented migrants were mainly seasonal labor migrants who left their families back home in their countries of origin. However, a body of contemporary migration studies literature shows a changing pattern of today's migration and the undocumented migrant family (Ryo, 2013). The trend in undocumented migration has shifted from a population of predominantly single male migrants working seasonally to larger numbers of women and children striving for settlement. For instance, Massey (2008) demonstrates that increasing the number and composition of the undocumented population in the United States comes as an unintended result of changes in immigration policies concerning a tightening of the border and strict enforcement of immigration regulations. As seasonal migration became more costly and dangerous in the 1990s, and early 2000s, increasing shares of families accounted for undocumented settlement in the United States (Gonzales, 2009). The similar mechanism of the production of the undocumented 
population in the European Union has been shown in several studies (Donato, Armenta, 2011, Düvell, 2006). The trend towards undocumented settlement has given rise to a population of undocumented migrant children that grow up in poverty and with uncertain futures. The latter is connected with some migrant and humanitarian crises. There is particular concern in immigration countries about the increasing number of unaccompanied minors (or separated children) arriving both as refugees and labor migrants. The UNHCR (2014: 15) defines unaccompanied minors as children under 18 years of age who are outside their country of origin and separated from the both parents or their previous legal/ customary caregivers. The current migrant crisis in Europe trends highlights the difficulties in gathering a reliable source of data on this category of undocumented migrant children. The media coverages stress sudden and dramatic situations that are related to increases in human trafficking and disappearances from reception centers. Although potential data sources on undocumented child immigration are compromised, there is a broad consensus of opinion on this issue that the number of unaccompanied minors is increasing, but only a disproportionate percentage of them may claim asylum.

\section{The dichotomy of understanding undocumented migrant child between "to be" and "to become"}

There are certain questions about undocumented migrant childhood that should not be evaded. What is the responsibility of a receiving society to undocumented migrant children when they come under age at which they legally become adults and are responsible for their actions? What does it mean to provide children with rights and protections that ultimately expire? There is a stark contrast between the legal position on undocumented childhood and adolescence and that of social sciences. The legal perspective is situated around two major components - minors and undocumented, whereas the sociological perspective derives from a transitional nature of childhood and its cultural diversity.

Being undocumented means that a person does not have the necessary documents, especially permission to live and work in a foreign country. However, it is the very difficult concept to define adequately in reference to the situation of children. The International Convention on the Rights of the Child stipulates that minors have to be protected and provided with care. Unlike adult undocumented migrants, children obtain a residence permit and receive support and education before reaching early adulthood. However, there are no extending rights to un- 
documented youth once they are coming of age. Moreover, many authorities use medical tests such as dental examination or x-rays of clavicle to verify someone's age and decide upon her/his status (Hunter, 2001). Thus the legal perspective is heavily relied on a category ascribed to an official age limit.

From the sociological point of view, experiences of childhood vary widely across cultures and contexts, which means that an official age limit does not always correspond with the cultural idea of transition to adulthood (Corsaro, 2011). Moreover, the degree of variation concerning the social recognition and non-recognition a transitional phase of adolescence is more problematic than other stage of the life cycle, because adolescence is merely understood contextually, even the social stage of adolescent coincides approximately with physical puberty (Arnett, 2000). Neither does the notion of adolescence as a model phase of separation and conflict, popularized by influential Western psychologists, fit in cultural varieties of adolescence elsewhere. In fact, nor does the official age limit as a worldwide standard. Several countries define the age at which someone legally becomes an adult between 16 and 21 years. And finally, there are also important differences in the individual grown up and social upbringing processes of every child, which create a possibility that an adolescent of 16 years old may be more mature than an 18 -year-old adult.

According to the legal perspective on minors, they are never classified as voluntary migrants (Halvorsen, 2002). It puts an emphasis on two elements; children do not make an independent decision to migrate and they do not have the necessary resources to undertake a voyage on their own. Moreover, they are not responsible for their actions as minors. Being unaccompanied is thus the most complex concept to grasp the importance of interpretation. The definition of unaccompanied children emphasizes the absence of the parents or previous legal caregiver. However, the criminal phenomenon of trafficking of minors for exploitive purposes imposes on a strict interpretation of this concept (Wernesjo, 2012). Authorities have to determine whether the accompanying adult is the appropriate caregiver under tradition and law. This task is particularly demanding, when there is no available documentation to verify alleged ties. The way of identifying migrant children is hence adult-centered, even though there is an effort made to protect them from abuse and exploitation.

From the sociological perspective, the developing nature of the child is considered to be intermediate the extreme of virtually permanent adult authority and the extreme of late adolescent autonomy (James, Prout, 1990). In this sense, the emphasis is laid on rational adults with children waiting to be processed through the particular rite of passage that socialization within a society is demanded. Migra- 
tion often involves the breakdown of family and other social structures that provide the basic frameworks for socialization. For undocumented children (or unaccompanied in particular), the lack of adult role models and the absence of normal socialization contexts that mediate between normal dependence-independence issues can be very concerned. The independency that many undocumented children has to develop in order to survive in the living and fleeing circumstances does not correspond with any notions of the ideal childhood based on the dependency upon significant others (adults). The idea that children (or even adolescents) may exercise unsupervised choice is not only socially outlandish, but dangerous. Thus adults are empowered to act for minors and in their best interest (Jenks, 1996). The problem is in making an accurate judgement where the line justifying adult intervention should be drawn. The ideal childhood, as conceptualized in much contemporary legislation, is perceived as one where all children are shielded from the pitfalls of a precarious living (UNHCR, 2014). In reality, a living situation undocumented migrant children experience in everyday life and towards their future perspectives sharply contrasts with the ideal childhood in a such way as it is constructed either in Europe or North America.

There is also another concern. It is now commonplace to view children as economically unproductive and adult-dependent (Zelizer, 1985). Outside Europe and North America, however, many children do work and are expected to be economically useful, contributing substantially to the household from an early age (Morrow, 1996). Moreover, being born often incurs a debt of gratitude that involves the child in lifelong obligations to family. This anticipated return can play an important role in making a migratory decision. Many unaccompanied minors come with some hopes and expectations to the host country. In particular, they believe that they will be able to fulfill their obligations to parents and other family members, to whom they possibly made important promises. The difficulty in keeping their promises is often seen as a source of distress and loyalty conflicts, because they perceive themselves as collaborators who are expected to assume their fair share of family duties. This attitude towards children is excluded from the conventional view on childhood in Europe and North America, where children are protected from the necessity to earn money to support family.

The legal perspective, entitled to provide temporary protection until the child attains the legal age, is dedicated to minimal standards of care and reception, and yet a serious neglect of social standards of child nurturing and migrant incorporation. The major obstacle is that relied on the legal perspective one may lose sight of the development nature of childhood. The uncertainty that follows undocumented migrant children' everyday living has dire consequences for the rest of their lives. 
Ideally each child should be protected by guaranteeing her or him two aspects: the right "to be" and the right "to become." The right "to become" means that the law is used in a way that would protect the child from any improper restriction upon her/his life choices as an adult. ${ }^{2}$ In reality the acquisition of citizenship in order to achieve a legal status formally equal to that of the native-born is a critical part of one's incorporation process into an adult life in the receiving society (Enriquez 2015). Naturalization will provide a secure legal basis to children on which to make decisions upon their life perspectives, but the harsh realities of undocumented migrant life are too often bounded to the limbo of the stateless person until they reach legal age and eventually immigration courts decide in favor of their request. Up to this point of time undocumented minors will not be certain of their future in the receiving country.

\section{Undocumented childhood and delayed incorporation}

Undocumented children not only live in a daunting life situation as strangers in another country, but also face other risks due to their uncertain future as they try to find a balance between unprotected and protected social contexts. Their initial process of incorporation into a receiving society is polluted by the stigma of unauthorized entry. Thus attaining legal residential permission and naturalization, both are widely recognized in the scholarly literature on integration as milestones in achieving societal membership and reducing marginality, are expensive and complex (Wong, Garcia, 2016). Moreover, their initial incorporation processes will take much longer than for less marginalized migrant groups (Bean et al., 2011). Furthermore, their migratory experiences involve multiple losses that distract them from incorporation. They are usually sequentially traumatized by tragic and stressful events before the flight from their home country and during their flight to the host country, and even after their arrival in the host country they still might encounter awkward experiences. In addition to their migratory experiences in a diverse aspects, they are usually deprived of parental assistance because of

2 The migratory experience of children includes in what Feinberg (1980) calls "rights to an open future." He distinguishes two categories of rights: dependency rights and rights in-trust. The former are rights that originate from the child's incapacity to fulfill her basic necessities such as food and clothing. The latter are rights that the child is not able to exercise yet, but that should be protected in a way that suggests their usage by the adult that the child will become. These rights are violated when someone decides for the child in a way that would close his/her alternatives. In many cases, however, the right to "an open future" is impossible to exercise, because each intervention is not neutral about the reduction of the future opportunities of the child. 
their separation from them, or parents, whose unauthorized themselves, tremble with the fear of deportation. Last but not least, for all migrants, and certainly for children, migration involves the confrontation with the unfamiliarity of the new society, including multiple barriers such as language, habits, rules and customs. This means that undocumented migrant children are severely disadvantaged.

Acculturation stress comes as a predictable consequence of disadvantaged position, when children work to adopt in the new environment (Berry, 1988). Their legal status, together with other barriers, might render the immediate impressions of alienation and marginality. The living circumstances of undocumented migrant children are little comfortable to copy with acculturation stress, since some of them might live in overcrowded refugee centers, while others live with their relatives in shadows. They may not always receive any substitute care and the uncertainty about the future dominates their lives in such a manner that it may deteriorate acculturation stress and other psychological problems such as depression (Gonzales et al., 2013).

The disruption and insecurity inherent to undocumented status may thus affect the social and psychological adjustment, making the process of incorporation delayed. Transitional membership statuses among migrants usually pose a dilem$\mathrm{ma}$ in balancing between integration into the host society and disintegration from the society left behind, whereas unauthorized entries means that their lives are vulnerable and precarious (Enriquez, 2015, Donato, Amada, 2011). For children, the experience of becoming undocumented put them at greater risk for the rest of their lives. In conclusion, loss of the sense of security and well-being associated with uncertain status may produce delayed, detoured, and derailed life trajectories.

\section{Belonging: public schooling and undocumented status}

The place of the children of migrants in a society has been always centered around the key issue of integration (Portes, Rivas, 2011). Especially the focus is on the bedrock issue in integration policy - how migrant children can become engaged citizens of tomorrow. Proposed solutions to a problem are usually addressed to prolonged exposure to mainstream receiving culture and institutions of a host society as supplemental sources of influence upon downward assimilation (Alba, Nee, 2003). However, first membership experiences with the host society reflect well or badly on migrants involved. Entry, legalization and naturalization carry important implications for delayed or even blocked assimilation of children into the receiving country. 
Rules on naturalization of the migrant generation and on birthright for the second generation has come under close inspection recently, since many members in the country of immigration have found cultural otherness as the possibility of trouble for a national identity and security (Spencer, 2016). A general lowering of society's acceptance of undocumented migration has thus accompanied. Permanent fear of adverse immigration consequences and experienced the feeling of social isolation have a dramatic impact on possibilities that socially disadvantaged migrant children will overcome obstacles of the inferior social status and take full advantage of public schooling in the receiving country. Stigmatized by their uncertain immigrant status, children may experience the social world ruled by norms and institutions as absurd and morally unstable, because they feel excluded from the membership.

Migrant children assimilate into the dominant normative patterns of the receiving society through the participation in everyday practices in societal institutions (Portes, Rivas, 2011). These institutions are not static but changing over time in the dynamic interplay between individual or group agency, institutional traditions and discourses, societal practices and material conditions. The multiple transformation that immigrant children experience have dramatic impacts on their identity formation, social network patterns, aspirations and expectations, as well as social and economic mobility. The context of reception thus provides more nuanced approaches on how immigrant children are channeled into different segments of society than a focus on the linear process of assimilation based on human capital gaining. The non-legal status causes undocumented children to do less well than other children of immigrants (Bean et al., 2011). In particular, when they transit from de facto protected (as minor) to unprotected status (as adult). In his research on undocumented immigrant children in the United States, Gonzales (2011) shows that there is a considerably high risk that a lifetime of social vulnerability, without a citizenship status, will create an underclass of children who have remote chances to overcome the handicap of marginal membership before reaching out their adulthood. In the European Union, the Platform for International Cooperation for Undocumented Migrants (PICUM, 2008) has also warned that careful thoughts about the conditions of undocumented migrant entry and assimilation mode are relatively rare, while the barriers to institutional access and social services are common. The conclusion is that undocumented childhood should not be a barrier to the use of basic rights for health, education and legal protection. However, it is unfortunate enough that the practice does not seem to follow the major recommendation for a change in the treatment of undocumented migrant children. 
The public school system has been always seen as the principal institution that plays a critical role in educating and integrating migrant children into the very fabric of society (Portes \& Rivas, 2011). The school conjures up the cultural imagination of nation that shapes immigrant pupils' understanding of their place in society. Moreover, in school, migrant children come to meet native-born teachers and peers as well as other foreign-born newcomers (like themselves) from different parts of the world. It creates perceptions of where they belong to. Furthermore, this secondary socialization mechanism is by far different what adult migrants encounter. Children grow up with the native-born, while adult migrants absorbed into low-wage markets and ethnics enclaves are usually separated from the contacts with members of the receiving society. Therefore, the school promotes an unique opportunity for the acculturation processes of migrant children.

For undocumented migrant children, however, their uncertain status places them in a developmental limbo. They have the legal right to elementary education, but other stages of education are usually problematic, because of its costs and legal obstacles (Olivas, 2012). In fact, they move from inclusion (protected status of minor) to exclusion (unprotected status as adult) during the final days of secondary education. Moreover, legal restrictions keep them from legal work or applying for financial aid that will help to support their further educational ambitions. Studies show that undocumented status depresses educational aspirations (Bean et al., 2011; Gonzales, 2011). Undocumented status also highlights the gap between the role of elementary education in the development and integration of children and limits that shatter their educational trajectories. The difficulty in continuing education sensitizes undocumented late adolescents in the reality that they are barred from further integration into society. In the words of Gonzales (2011), in those days, they are learning to be illegal.

\section{Undocumented status and transition into adulthood}

Generally, life-course scholars point out that the transition into adulthood is taking much longer today (. It means that young people usually continues their tertiary education and delaying both exit from the parental household and entry into full-time work. They also defer the decision on getting married and becoming a parent. These are usually referred to the five of milestones that put the stamp on the transition into adulthood. The transition thus shows the contradictory roles of childlike dependency and adult independence. 
As it has been mentioned before, undocumented status makes the difficulty in following the normative pathways into adulthood, because undocumented migrant children have not enough of normalcy that provides the institutional frameworks by which adolescents are socialized into the roles that they are expected to occupy as adults (Rumbaut, Komoie, 2010). Legal restrictions leave them unable to complete some transitions, while deportation remains a constant thread of coming of age. Therefore, the basics of adolescence such as a choice of social role and the search for an adult identity cannot proceed normally. The chronic uncertainty about the future undermines their confidence about long-term prospects. As a result, they do not have the certain degree of ability to choose convenient routes to adulthood. As Gonzales (2011: 605) notices, while the public school context helps to sustain their acculturation process and fosters expectations and aspirations that bind undocumented children to the receiving society, it contradicts with what awaits them in adulthood. There are different meanings to undocumented status; whereas one stresses the school as a protected space that gives rise to higher hopes for the integration into society, the other one animates the experience of illegality at late adolescence. They learn in a heartbreaking way that it will be difficult to realize hopes and plans they came to the host country, because they may never acquire a definitive residence permit. Once committed to the belief that their integration is possible, experience their downfall as some positive outcomes after school are broken.

\section{Children at the center? Children as a minority group}

The case of undocumented migrant children underscores the need to develop a solution not limited to an ethnic identification and suggestive of alternative modes of belonging. At the core of current child welfare policies, however, lies powerful blood bias - the assumption that blood relationship is crucial for the entitlement to membership of a cultural/national group. Blood is recognized as a significant factor in shaping the quality of a collective identity of individuals. Identity thus becomes a well-defined entity, which is based on the legitimacy of birthright. Even in the age of migration, the birthright is the most acceptable way to obtain membership. Though, the cultural identity of the migrant child has always been a contentious issue in the country of immigration (Portes Rivas, 2011). ${ }^{3}$

${ }^{3}$ On the one side, renouncing the separated cultural identity of the immigrant child is seen as crucial for her assimilation and failure to do so, is regarded as indicative of a desire for separatism. On the other side, the alternative view maintains that immigrant children need their own cultures to develop identity and self-esteem. 
The presumed lack of child's autonomy to state which group she or he belongs to, eliminates another identity option. The issue of belonging to a group is thus identified with a matter of being owned by the group. It determines typical ways of dealing with the cultural identity of a small child. There is an implicit assumption that the small child has a cultural identity from birth. The cultural identity of the small child is just the same as the cultural identity of her/his parents. Thus the cultural identity of the child is readily understood as a quasi-genetic entity that is passed through the ties of kinship. It creates a certain belief that the entitlement to membership of a cultural/national group and the absorption of its culture follow an almost genetic destiny. These beliefs are deeply entrenched in law and culture (Montgomery, 2009). Either of them puts an emphasis on both aspects: parents' rights to guide their children and children' rights to their roots and heritage. It contributes to a deeply shared belief that children belong with and to their biological parents.

On the contrary, children's vital needs (outside the biological family) are for someone who is committed to and capable of caring for them today and in their future. In the event that things go terribly wrong such as those which undocumented migrant children experience, they need to be provided not only protection and support, but an alternative mode of belonging. However, for undocumented migrant children, who face the vulnerability as children and undocumented foreigners, the process can seem additionally complicated. Firstly, they are more likely to inherit socially inferior status of their parents. Secondly, if they crossed borders alone, they will be classified according to their age as a person who is not responsible for her/his actions until she or he legally becomes an adult. Thirdly, they are bounded to a culture of origin. Their situation exposes the truth that treating them as belonging, in an essentialist way, to their kin and national/cultural group, often ends up with policies that prevent children from truly belonging to anywhere (Spencer, 2016; Wernesjo, 2012). It leads to the application of lower quality of care standards compared to the care for other children and adolescents, which, of course, raises tremendous ethical questions. Do we really care for children? If so, why do we have certain cultural preferences?

Some sociologists of childhood thus suggest that children need to be treated as a minority group beyond his/her primordial ethnic affiliation, yet with respect to cultural diversity (Jenks, 1996). The empowerment of unequal childhood could protect children as a minority group against the deprivation of their needs in the name of collective interests. The role of the child will be used as a rationale for the limitation of individual incentives and the vulnerability to restrictive cultural practices. Therefore, the dedication to children's best interests should not be 
limited to the connection to the past - their birth heritage and cultural heritage, but involves her/his individual needs and rights for today and in the future. The strength of this suggestion derives from the experience of the cultural diversity of childhoods that acquires to give children (seen as active subjects) a legal status that will protect them from cultural violence, gender discrimination and unequal treatment (Mayall, 1996). The weakness is that the Western liberal discourse on diversity emphasizes the importance of autonomy and identity as the precondition for any resolution of minority rights (Kymlicka, 1996). In the case of children, there are certain obstacles to the solution offered by liberal thinkers. Firstly, it contains a problem of determining the child's capacity to choose autonomously and of establishing the limits of parenthood. Secondly, it causes a lot of problems to recognize the identification of the cultural identity in relation to children unless the cultural identity of the parent determines a cultural identity of the child.

Nevertheless, there is a solution. The degree of capacity for autonomy and identity that children have will depend on their age. Therefore, the transition is a key concept that refers to the passage of the child from being a non-autonomous individual to a young person who is able to decide for herself/ himself. It is odd enough, however, that at the same time, when undocumented migrant youth come of age they entry into a stigmatized and passive identity, which not only prevent them from gaining from social, educational and occupational activities, but it disenfranchises them to fight for changing their fate. It means that their further legal incorporation (as early adults) strongly depends on current trends in immigration policies and political climate around. Minority status which underlines the importance of the transitional process of childhood could give them freedom from political caprice and xenophobic propagandas (which are not willing to recognize their rights, once they reach the age). Therefore, it is highly recommended to take the transitional process serious as the starting point in the discussion about undocumented migrant children' rights for their incorporation into the receiving society.

\section{Conclusion}

While scholars generally claim that most young people today face some difficulty managing adolescent and adult transitions, undocumented migrant youth face added challenges (Gonzales, 2011). Legislations agree to the need of support and care for minors, but all these rights cease when the minor comes of age. They have some access to basic social institutions in an early adolescence, but when they transit into an adulthood they are denied everyday participation in most 
institutions of mainstream life. It means that they are put into overwhelming powerless social situation and they lose every right to support. Moreover, these young people are likely to remain in the receiving country, because of the severe limitation of other options. As a result, they have to learn live as a disfranchised underclass of young adults, who risk to be repatriated to their country of origin or another country. In a certain way, one may call it as "wasted young lives and life opportunities". Furthermore, all socialization efforts made by teachers and social workers to integrate them into the receiving society are hampered by a lack of hospitality. The negligence of sociological perspective on undocumented migrant children concerning their transition to adulthood results in allowing these people to enter very endangering and abusive situations as undocumented immigrants and young adults without supportive social networks. These accumulations indicate high risks for dysfunctional behaviors. In the end, differences in quality of child care and welfare based on the minor's legal status and not on her/his needs call for careful thoughts about the moral condition of society and its dedication to humanistic values.

\section{References}

Alba R., Nee V. (2003). Remaking the American Mainstream: Assimilation and Contemporary Immigration. Cambridge.

Arnett J.J. (2000). Emerging adulthood: A theory of development from late teens through the twenties. "American Psychologist" 55.5, pp. 469-480.

Bean F.D., Leach M.A., Brown S.K., Bachmeier J.D., Hipp J.R. (2011). The educational legacy of unauthorized migration: Comparisons across U.S.-immigrant groups in how parents' status affects their offspring. "International Migration Review" 45.2, pp. 348-385.

Berry J.W. (1988). Acculturation and psychological adaptation: A conceptual overview. [In:] J.W. Berry, R.C. Annis (eds). Ethnic Psychology: Research and Practice with Immigrants, Refugees, Native Peoples, Ethnic Groups and Sojourners. Lisse.

Bhabha H.K. (1992). Double visions. "Artforum” January 1992, pp. 88.

Bühler-Niederberger D. (2010). Introduction: Childhood sociology, defining the state of the art and ensuring reflection. "Current Sociology" 58.2, pp. 155-164.

Cannella G.S. (2002). Global perspectives, cultural studies, and the construction of a postmodern childhood studies. [In:] G.S. Cannella, J.L. Kincheloe (eds), Kidworld Childhood Studies, Global Perspectives, and Education. New York, pp. 3-20.

Corsaro W.A. (2011). The Sociology of Childhood. $3^{\text {rd }}$ ed. London.

Donato K.M., Amada A. (2011). What we know about unauthorized migration. "Annual Review of Sociology" 37, pp. 529-543.

Düvell F. (2006). Undocumented migration in Europe: a comparative perspective. [In:] F. Düvell (ed.). Illegal Immigration in Europe. Beyond Control. New York. 
Enriquez L.E. (2015). Multigenerational punishment: shared experiences of undocumented immigration status within mixed-status families. "Journal of Marriage and Family" 77.4, pp. 939-953.

Feinberg J. (1980). The child's right to an open future. [In:] W. Aiken, H. LaFollette (eds). Whose Child? Children's Rights, Parental Authority, and State Power. Totowa.

Gonzales R.G. (2009). On the rights of undocumented children. "Society" 46.5, pp. 419-422.

Gonzales R.G. (2011). Learning to be illegal: undocumented youth and shifting legal contexts in the transition to adulthood. "American Sociological Review" 76.4, pp. 602--619.

Gonzales R.G., Suárez-Orozco C., Dedios-Sanguineti M.C. (2013). No place to belong. contextualizing concepts of mental health among undocumented immigrant youth in the United States. "American Behavioral Scientist" 57.8, pp. 1174-1199.

Halvorsen K. (2002). Separated children seeking asylum: the most vulnerable of all. "Forced Migration Review" 12, pp. 34-36.

Hunter A. (2001). Between the domestic and the international: the role of the European Union in providing protection for unaccompanied refugee children in the United Kingdom. "European Journal of Migration and Law" 3.3, pp. 383-410.

James A. (2007). Giving voice to children's voices: practices and problems, pitfalls and potentials. "American Anthropologist" 109.2, pp. 261-272.

James A., Prout A. (1990). Constructing and Reconstructing Childhood. Contemporary Issues in the Sociological Study of Childhood. London.

Jenks Ch. (2009). Constructing childhood sociologically. [In:] M.J. Kehily (ed.). An introduction to childhood studies, 2nd edition. Maidenhead.

Kincheloe J.L. (2002). The complex politics of McDonald's and the new childhood: colonizing kidworld. [In:] G. S. Cannella, J. L. Kincheloe (eds), Kidworld Childhood Studies, Global Perspectives, and Education. New York, pp. 75-121.

Kymlicka W. (1996). Multicultural Citizenship: A Liberal Theory of Minority Rights. Oxford.

Massey D. (1994). Space, Place and Geometry. Cambridge.

Massey D.S. (2008). New Faces in New Places: The New Geography of American Immigration. New York.

Mayall B. (1994). Children's Childhoods: Observed and Experienced. London.

Mongomery H. (2009). An Introduction to Childhood: Anthropological Perspectives on Children's Lives. Malden.

Morrow V. (1996). Rethinking childhood dependency: children's contributions to the domestic economy. "Sociological Review" 44.1, pp. 58-77.

Olivas M.A. (2012). No Undocumented Child Left Behind. Plyler v. Doe and the Education of Undocumented Schoolchildren. New York.

PICUM (2008). Undocumented Children in Europe: Invisible Victims of Immigration Restrictions. Brussels.

Portes A., Rivas A. (2011). The adaptation of migrant children. "Future Child" 21.1, pp. 219-246.

Rumbaut R.G., Komaie G. (2010). Immigration and adult transitions. "Future of Children" 20.1, pp. 39-63.

Ryo E. (2013). Deciding to cross: norms and economics of unauthorized migration. "American Sociological Review" 78.4, pp. 574-613.

Spencer S. (2016). Postcode lottery for Europe's undocumented children unravelling an uneven geography of entitlements in the European Union. "American Behavioral Scientist" 60.13, pp. 1613-1628. 
UNHCR (2014). The Heart of the Matter. Assessing Credibility when Children Apply for Asylum in the European Union. Geneva.

Uprichard E. (2008). Children as 'being and becomings': children, childhood and temporality. "Children and Society" 22.4, pp. 303-313.

Wernesjo U. (2012). Unaccompanied asylum-seeking children: whose perspective? "Childhood" 19.4, pp. 495-507.

Wong T.K., Garcia A.S. (2016). Does where I live affect whether I apply? The contextual determinants of applying for deferred action for childhood arrivals. "International Migration Review" 50.3, pp. 699-727.

Zelizer V. (1985). Pricing the Priceless Child: The Changing Social Values of Children. New Haven. 